\title{
CALIBRATION OF THE HEAT BALANCE MODEL FOR PREDICTION OF CAR CLIMATE
}

\author{
Jan POKORNÝ, Jan FIŠER and Miroslav JíCHA
}

\begin{abstract}
In the paper, the authors refer to development a heat balance model to predict car climate and power heat load. Model is developed in Modelica language using Dymola as interpreter. It is a dynamical system, which describes a heat exchange between car cabin and ambient. Inside a car cabin, there is considered heat exchange between air zone, interior and air-conditioning system. It is considered $1 D$ heat transfer with a heat accumulation and a relative movement Sun respect to the car cabin, whilst car is moving. Measurements of the real operating conditions of gave us data for model calibration. The model was calibrated for Škoda Felicia parking-summer scenarios.
\end{abstract}

\section{INTRODUCTION}

A car cabin is a small enclosed space, which should provide comfortable indoor climate for persons inside, although the thermal resistance/insulation of walls is relatively low compared to buildings. Generally car cabin climate is more sensitive to the change of weather conditions. In summer the solar intensity substantially affects a thermal comfort and climate in car cabin. It is due to the high ratio of transparent surfaces transmitting solar radiation energy inside. Climate control of such compartments requires consideration of dynamical heat transfer phenomena. Konz [3] developed a dynamical model of VW Polo car cabin to study various air conditioning strategies. Wagner [5] introduced a method to predict the temperature stratification inside a passenger compartment for various types of cars. Arici [1] developed a design tool for climate control system minimizing the time-consuming procedures for integrating a prototype air conditioning system. In automotive industry, there are used commercial softwares as Theseus-FE [4] or RadTherm to simulate heat transfer inside car cabin.

The paper presents the car cabin model for prediction of car climate, mainly air zone temperature of air inside a passenger compartment. The model is designed for prediction of car climate, when the operating and weather conditions are known. It is heat balance model considering 1D heat exchange among ambient, passenger compartment and air conditioning system. The model was tested on four test cases representing scenario of parking during summer day. The test vehicle was Škoda Felicia with dark blue painting see Figure 1, on the left. More details about measurements are in the chapter 4.

\section{Heat Balance Model of Car Cabin}

It is considered $1 \mathrm{D}$ heat transfer with a heat accumulation in the nodes. The car cabin model consists from exterior (index $E$ ), interior (index $I$ ) and airzone (index $A$ ) nodes.

\footnotetext{
- Jan Pokorný, Jan Fišer, prof. Miroslav Jícha, CSc., Department of Thermodynamics and Environmental Engineering, Faculty of Mechanical Engineering, Brno University of Technology, Technická 2896/2, 616 69, Brno, e-mail: ypokor25@stud.fme.vutbr.cz
} 
Cabin is split into 10 parts: Windshield, Rear glass, Left and Right side glass, Bulk, Trunk door, Left and Right doors (opaque surfaces), Roof and Floor. Each part has its own exterior and interior node and heat balance equations (1-2). It is considered only one airzone node for the whole compartment, see equation (3). The heat transfer model includes an air conditioning system (index $\mathrm{K}$ ), which regulates temperatures and relative humidity inside a passenger compartment.

At the outer surface of cabin, it is considered heat exchange between ambient and exterior by shortwave and longwave radiation and convection. Heat balance (in watts) at exterior surface is defined as

$$
c_{E} m_{E} \frac{d t_{E}}{d \tau}=Q_{E, \text { rad }}+Q_{E, \text { conv }}+a Q_{s r}+Q_{E, \text { cond }},
$$

where $c[\mathrm{~J} / \mathrm{kgK}]$ is specific heat capacity, $m[\mathrm{~kg}]$ is mass, $\tau[\mathrm{s}]$ is time, $\mathrm{T}\left[{ }^{\circ} \mathrm{C}\right]$ is mode temperature and $Q_{E, \text { rad }}$ is longwave radiation heat flow between ambient and car cabin, $Q_{E, \text { conv }}$ is convective heat flow between ambient air and car cabin, both calculated by empirical formulas from [3]. $a Q_{s r}$ represents absorbed solar energy by cabin surfaces and $Q_{E, \text { cond }}$ is conductive heat flow between exterior and interior node.

Inside a compartment it is considered heat exchange among interior (convection, radiation), air zone, air conditioning (convection), human (radiation, convection evaporation and respiration) and ambient (transmitted solar radiation). Heat balance at interior surface is

$$
c_{l} m_{l} \frac{d t_{l}}{d \tau}=Q_{l, c o n v}+\mu Q_{s r}-Q_{E, \text { cond }}+Q_{H, \text { rad }}
$$

where $Q_{I, \text { conv }}$ is convective heat flow between airzone and interior node. $\mu Q_{s r}$ represents transmitted solar energy.

Heat balance in airzone node depends on the heat energy coming from air conditioning, human surface and heat transfer between air and interior surfaces by convection.

$$
m_{A} c_{A} \frac{d t_{A}}{d \tau}=\left(i_{K}-i_{A}\right) \frac{d m_{K}}{d t}-m_{A} \frac{d i_{A} d x_{A}}{d x_{A} d t}+Q_{H, \text { conv }}-Q_{l, \text { conv }},
$$

where $x_{A}$ is specific humidity of air zone, $\left(i_{K}-i_{A}\right)$ is the change of specific enthalpy in airzone, $Q_{H, \text { rad }}=70 \mathrm{~W} / \mathrm{m}^{2}$ and $Q_{H, \text { conv }}=30 \mathrm{~W} / \mathrm{m}^{2}$. i.e each occupant produces $100 \mathrm{~W} / \mathrm{m}^{2}$ (i.e. seating activity). Both heat loss by respiration and evaporation are not considered in the model. A car climate is defined by airzone temperature and airzone humidity. The specific humidity of air zone $x_{A}$ is calculated by the moisture mass balance equation

$$
m_{A} \frac{d x}{d \tau}=\left(1+x_{A}\right) \frac{d m}{d \tau}\left(\frac{x_{K}-x_{A}}{1+x_{K}}\right)
$$

\section{3. ŠKoda Felicia PaRAmeters}

Škoda Felicia material composition was estimated from the test vehicle and the values of material properties were taken from Theseus-FE material properties database. Since most of cabin parts are composed from more materials (multilayered), Thermal insulation 
and specific heat capacity of each part was pre-calculated in Excel. Real Škoda Felicia Combi geometry was simplified into the parameterized geometry, which was defined as follows: $\alpha=32^{\circ}, \beta=34^{\circ}, y=66^{\circ}, A=3.3 \mathrm{~m}, B=1.42 \mathrm{~m}, C=0.72 \mathrm{~m}, D=0.38 \mathrm{~m}$, see Figure 1, on the right.
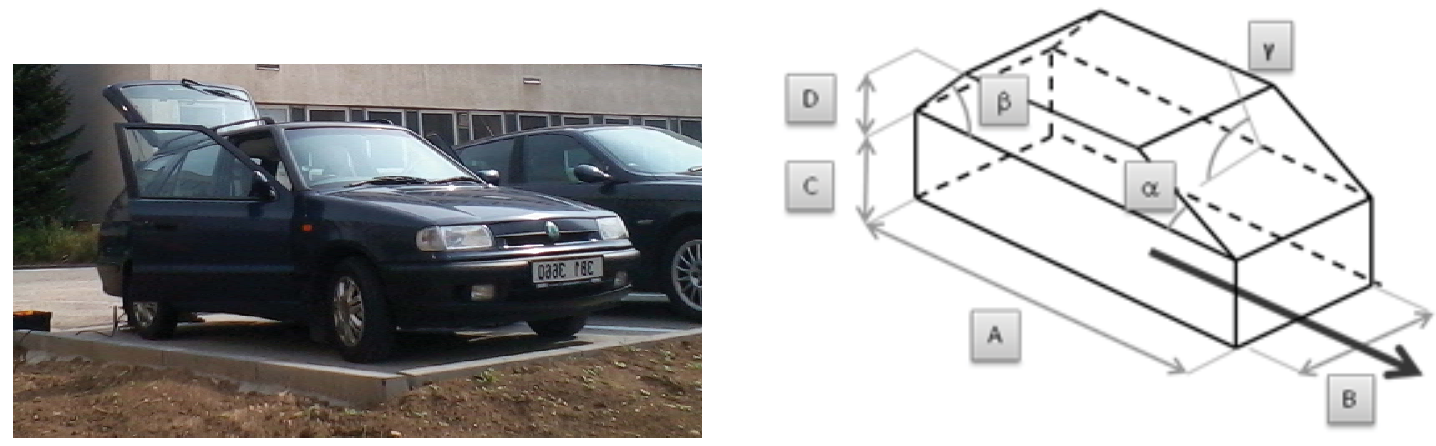

Figure 1: Test vehicle Škoda Felica and its parameterized geometry

Where $\alpha$ is windshield angle, $\beta$ is rear glass angle, $y$ is side glass angle, $A$ is length, $B$ is width, $C$ is height of door panels and $D$ is height of door glasses. Black arrow denotes a car orientation vector. The geometry parameters are important for the calculation of shortwave radiation (it depends on the mutual position of each car body part and Sun). Important characteristics are shortwave radiation absorptivity $a$ and transmissivity $t$, and longwave radiation emissivity. The letter is equal to longwave radiation absorptivity by the Kirchhoff's law of thermal radiation. Airzone volume of cabin is very important parameter for calculation of ventilation. It is expressed from the volume of parameterized geometry defined as

$$
V_{\text {cabin }}=A \cdot B \cdot C+\frac{D}{3}\left(S_{\text {roof }}+\sqrt{S_{\text {roof }} S_{\text {floor }}}+S_{\text {floor }}\right)=3.7\left[\mathrm{~m}^{3}\right]
$$

where $S\left[\mathrm{~m}^{2}\right]$ are surface areas. This volume includes interior equipment volume $0.15 \mathrm{~m}^{3}$ (seats, dashboard, etc), trunk volume $0.45 \mathrm{~m}^{3}$ and airzone volume, which completes the sum and it is equal to $3.1 \mathrm{~m}^{3}$.

\section{Measurements}

Measurements of case Parking-Summer was done in the backyard parking lot of Faculty of Mechanical Engineering in Brno, Královo Pole during $2^{\text {nd }}$ and $12-15^{\text {th }}$ of September 2011. Equipment and hardware used for measurements:

- Data loggers TESTO 435 and 735, ELSACO-PLC with PT 100 probes, TESTO combined probe (velocity, humidity, temperature) and wireless air temperature probes, Solar panel $12 \mathrm{~W}$ with 7Ah lead-acid accumulator, ACER laptop.

Data channels:

- Air temperature: Ambient, Under Hood, Trunk, Co-driver: Feet, Head, Torso, Passenger (behind driver): Feet, Head, Torso

- Surface temperatures: Solar panel and interior surfaces as Roof, Dashboard, Codriver seat, Right door, Windshield, Right glass

- Air velocity: at Co-driver's head position, at outlets of HVAC

- Relative humidity: Ambient, at Co-driver's head position

- Radiant temperature: at Co-driver's head position

- Global solar intensity on the Roof (horizontal plane) 
The solar intensity was derived from measurement of the solar panel power and it was calibrated by table of typical solar intensity during September in Brno (see Cihelka [2]). Air velocity at outlets of HVAC was measured for typical ventilation rates (II. and IV. step of fan controller) to estimate air mass flow coming into the cabin. Measured data were logged in TESTOs and ELSACO data loggers and then were exported into the Excel and filtered. The filtered measured data were used to define inputs and boundary conditions and also for the model calibration.

\section{Results AND Discussion}

A comparison of model predictions and measurements are presented in this chapter see Figure 2. The comparison is focused on the airzone temperature, because this parameter is one of the most important climate parameters. It was compared with the mean air temperature calculated as average of all air temperatures measured in cabin of the test car, namely head, torso and feet position at the co-driver and the rear left passenger seat. Boundary conditions used in car cabin model were:

a) Constant conditions

- Car position: Latitude $49.2^{\circ} \mathrm{N}$, Longitude $16.6^{\circ} \mathrm{E}$, Altitude $363 \mathrm{~m}$

- Car orientation: to the North-East (Azimuth $67^{\circ}$ )

- Car speed: $0 \mathrm{~km} / \mathrm{h}$ (parking)

- Air-conditioning and ventilation: switched off

- Occupants: 0 person

b) Variable conditions

- Date and Time (summer)

- Relative humidity of ambient air [\%]

- Ambient radiant temperature and air temperature $\left[{ }^{\circ} \mathrm{C}\right]$

- Air temperature inside trunk and engine space $\left[{ }^{\circ} \mathrm{C}\right]$

- Solar radiation intensity $\left[\mathrm{W} / \mathrm{m}^{2}\right]$
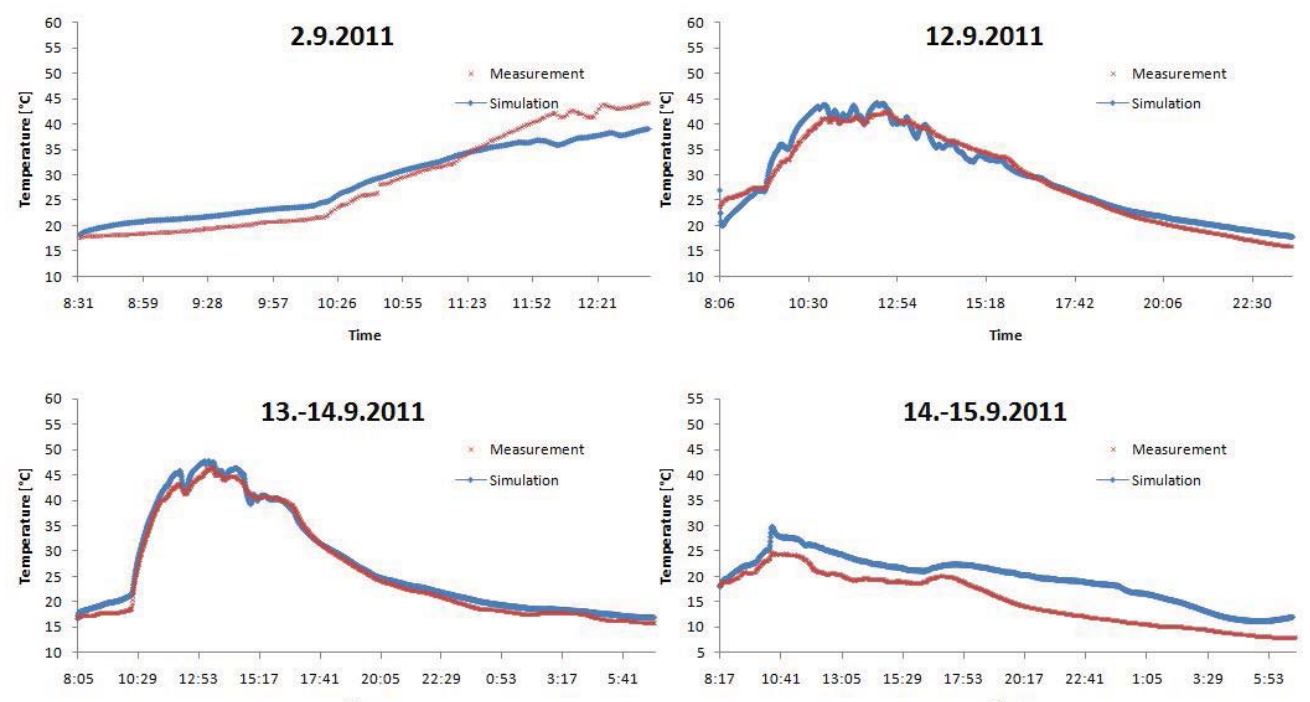

Figure 2: Four summer parking cases. Comparison of calculated airzone temperature (blue line) with averaged measured air temperature (red line) 
Measurements show that the main factor affecting airzone temperature is the solar radiation and ambient air temperature. The ambient radiant temperature is also very important parameter, but it is precise value during real operating conditions is hard to obtain. It depends on many factors: e.g. sky conditions (cloudiness, Linke turbidity factor, etc.), temperatures and materials of surrounding countryside, shadows etc. In the simulations ambient radiant temperature was assumed to be equal ambient air temperature. The model does not take in account effects of wind and precipitation. This fact can be reason why in test case 14.9.-15.9. differences between simulated and measured air temperature were higher, because this day was raining from 12:05 till 16:30 and it was relatively windy. The model is also limited by consideration of only one airzone for whole cabin, thus the air stratification effect (in summer parking test case was the temperature difference over $20^{\circ} \mathrm{C}$ ) cannot be described. Moreover to simulate a power heat load of cabin is necessary to calculate temperatures of exterior and interior surfaces. The exterior surfaces show a good agreement unlike some interior parts as Dashboard and Right door. It is due to the fact that geometry of interior is not considered explicitly (not defined geometry of seats, dashboard etc.). Even through the very simplified car cabin geometry, the prediction of air temperature inside car cabin shows a good agreement with measured data.

\section{Conclusions}

The parameterized model is able to predict a car climate and a power heat load on the car cabin during real operating conditions. If the characteristic of HVAC system is known then it is possible to simulate heating/cooling power to achieve a set point temperature. The accuracy of the model can be improved by definition of interior geometry as seats and dashboard. The model is valid for weather without precipitations, which strongly affect the heat transfer. It was done measurements during summer (parking case) and measurements of autumn test cases (driving: city, highway) is still ongoing. At the beginning of the new year some winter tests will be carried out to validate the model for the whole year weather condition of Central European climate.

\section{ACKNOWLEDGEMENT:}

This work is founded by Czech government project GA101/09/H050 and Brno University of Technology project BD13102016/2100. Consultation of technical aspects from Volkswagen AG Company is great acknowledged as well.

\section{RefERENCES}

[1] Arici O., Yang S., Huang D., Oker E.: Computer Model for Automobile Climate Control System Simulation and Application. Int.J. Applied Thermodynamics, Vol.2, (No.2), 2010, pp. 59-68

[2] Cihelka J.: Solární tepelná technika, Malina - Praha 1994.

[3] Konz M.: A Generic Simulation of Energy Consumption of Automobile Air Conditioning Systems. Ph.D. thesis - Port Elizabeth Technikon, 2002

[4] Theseus-FE: Theory Manual Version 4.0, P+Z Engineering GmbH - Munich, 2011. Available from WWW: <http://www.theseus-fe.com>

[5] Wagner S.: Idealisierte energetisch-analytische Abbildungsmethode der Temperaturschichtung bei der passiven Aufheizung in der Fahrzeugkabine, PKWKlimatisierung VI, Haus der Technik Fachbuch 107 - Essen, 2009, pp. 94-110 